\title{
ABORDAGEM ETNOMATEMÁTICA PARA TRANSFORMAÇÕES GEOMÉTRICAS A PARTIR DA TECELAGEM AFRICANA
}

\section{ETNOMATEMATIC APPROACH FOR GEOMETRIC TRANSFORMATION FROM AFRICAN WEAVING}

\author{
Thaciane Jähring Schunk ${ }^{1}$ \\ Instituto Federal do Espírito Santo - IFES \\ Lauro Chargas e Sá⿱ \\ Instituto Federal do Espírito Santo - IFES
}

\section{Resumo}

O Programa Etnomatemática de D'Ambrósio é um programa de apoio pedagógico que valoriza as culturas de determinada sociedade e seus conhecimentos adquiridos ao longo de sua existência. Além disso, podemos verificar que tal programa está intimamente relacionado à lei $n^{\circ} 10.639 / 2003$, a qual estabelece que todas as unidades de ensino básico devem inserir a história e a cultura africana e afro-brasileira no currículo escolar, em consonância com o resgate dos valores da diversidade étnico-racial brasileira. Nesse sentido, esta pesquisa apresenta e discute uma oficina ocorrida na I Semana da Consciência Negra e Indígena do Instituto Federal do Espírito Santo (Ifes), campus Viana, sobre transformações geométricas em estamparias africanas, no segundo semestre de 2017, com estudantes do primeiro e segundo ano do Curso Técnico em Logística Integrado ao Ensino Médio. O objetivo principal da oficina foi analisar as estamparias africanas para reconhecer as transformações geométricas presentes nos tecidos, além de realizar transformações por meio dos símbolos africanos para aflorar as habilidades de construções desses modelos. Para isso, passamos por três etapas: discussão sobre a importância das estamparias e símbolos na cultura africana - identificando as transformações geométricas nas estamparias - e exploração das transformações geométricas por meio dos símbolos africanos. O nosso método de análise da oficina foi constituído de questionário diagnóstico realizado antes e depois da proposta didática. Por meio desses questionários observamos que a oficina contribuiu positivamente para $o$ conhecimento dos alunos sobre a relação entre a estamparia africana e a matemática. Esta proposta de ensino baseado no Programa Etnomatemática e na lei ${ }^{\circ} 10.639 / 2003$ valoriza a cultura africana e pode incentivar outros profissionais da educação a realizar metodologias que evidencie essa lei.

Palavras-chave: Etnomatemática; África; Lei $n^{\circ}$ 10.639/2003; Transformações Geométricas.

\footnotetext{
${ }^{1}$ thacianeschunkj@gmail.com

2 lauro.sa@ifes.edu.br
} 


\begin{abstract}
D'Ambrósio's Ethnomathematics Program is a pedagogical support program that values the cultures of a given society and its acquired knowledge throughout its existence. And, we can verify that Law $n^{\circ} 10.639$ / 2003 establishes that all basic education units must insert African and Afro-Brazilian history and culture in the school curriculum, in line with the recovery of the values of Brazilian racial and ethnic diversity. In this sense, this research presents and discusses a workshop that took place in the I Week of the Black and Indigenous Consciousness of the Federal Institute of Espírito Santo (Ifes) campus Viana, about geometric transformations in African prints in the second half of 2017 with students of the first and second year of the Technical Course in Integrated Logistics to High School. The main objective of the workshop was to analyze the African stamping to recognize the geometric transformations present in the fabrics, as well as to make transformations through the African symbols to surface the construction skills of the transformations. To do this, we go through three stages: discussion of the importance of stamping and symbols in African culture - we identify geometric transformations in African stamping - we explore geometric transformations through African symbols. Our workshop analysis method consisted of a diagnostic questionnaire before and after the didactic proposal. Through this questionnaire we observed that the workshop contributed positively to the students' knowledge about the African and mathematical stamping relationship. This teaching proposal based on the Ethnomathematics Program and Law $\mathrm{n}^{\circ}$ 10.639 / 2003 has shown that it values African culture and can encourage other education professionals to carry out methodologies that demonstrate this law.
\end{abstract}

Keywords: Ethnomathematics; Africa; Law 10,639 / 2003; Geometric Transformations.

\title{
Introdução
}

Sabemos que o processo de construção das identidades nasce a partir da consciência das diferenças entre nós e o outro (CORENZA; MELQUIADES; SOUZA, 2016). Essas identidades, por vezes, são formadas por elementos históricos que não valorizam as culturas e as riquezas dos povos africanos, assim, é evidenciado, ao longo da história, uma suposta subalternização da África, remetendo-a somente à escravidão e à colonização. Na perspectiva de alterar esse cenário, a Lei 10.639/2003 (BRASIL, 2003) propõe a valorização, no contexto escolar, das identidades negras e sua inserção em currículos e em práticas educacionais. Também nesse movimento, as Diretrizes Curriculares Nacionais para a Educação das Relações Étnico-Raciais e para o ensino de História e da Cultura Afro-Brasileira e Africana (BRASIL, 2004), aprovadas pelo Conselho Nacional de Educação, em 2004, foram elaboradas para consolidar a referida lei nas escolas. 
Temas como a cultura afro-brasileira e a contribuição dos negros na formação da sociedade brasileira são relevantes para os estudos de todas as disciplinas, visto que o Brasil é formado não só a partir de heranças culturais europeias, mas, também, indígenas e africanas. Ainda assim, é possível verificar, nos currículos educacionais, que essas três contribuições - europeia, africana e indígena - não são contempladas de maneira igualitária, mesmo a África sendo apresentada, em muito materiais educativos, como o berço da humanidade, o continente-mãe.

Silva (2007, p. 490) comenta sobre a importância da valorização da diversidade cultural no ambiente escolar e em seu entorno:

A educação das relações étnico-raciais tem por alvo a formação de cidadãos, mulheres e homens empenhados em promover condições de igualdade no exercício de direitos sociais, políticos, econômicos, dos direitos de ser, viver, pensar, próprio aos diferentes pertencimentos étnico-raciais e sociais.

Acerca do campo da Matemática, especialmente, sabe-se que a África é um dos seus berços, pois o testemunho mais antigo conhecido sobre esta ciência, o osso Ishango, com mais de oito mil anos, foi encontrado no continente africano, tal evidência mostra números preservados por meio de entalhes no osso (EVES, 2004). De acordo com o contexto apresentado, este trabalho trata-se do recorte de uma pesquisa de Iniciação Científica $^{3}$, ainda em desenvolvimento, sobre Etnomatemática e práticas educativas para o Ensino Médio.

Inicialmente, realizamos um levantamento bibliográfico nos anais do ENEM Encontro Nacional de Educação Matemática - de 2013 e 2016, composto por 4.039 textos publicados, dos quais apenas 18 continham propostas didáticas ou relatos de experiência na perspectiva Etnomatemática com foco em África, o que corresponde, na verdade, à 0,45\% dos textos publicados (SCHUNK; SÁ, 2018). A maior parte dos trabalhos foi realizada com alunos do ensino superior, atingindo a porcentagem de 44,4\%. Com os alunos dos anos finais do ensino fundamental e do ensino médio, ambos, foram sucedidos $22,2 \%$ dos trabalhos. Já nos anos iniciais do ensino fundamental e com os discentes da educação de jovens e adultos, foram materializados, cada um, em 5,5\% dos trabalhos. Em relação aos campos da Matemática, $55,5 \%$ dos trabalhos foram sobre números e

\footnotetext{
${ }^{3}$ Plano de Trabalho PT00006577, com financiamento do Instituto Federal do Espírito Santo (Ifes). A pesquisa foi desenvolvida no âmbito do Grupem - Grupo de Pesquisa em Práticas Pedagógicas de Matemática, em parceria com o EMEP - Grupo de Pesquisa em Educação Matemática e Educação Profissional (http://emep.ifes.edu.br).
} 
operações; $22,2 \%$, sobre espaço e forma; $5,5 \%$, sobre álgebra; e, em 16,6\%, não foi possível identificar a área. Ainda, vale salientar que 38,8\% dos trabalhos utilizavam-se o Mancala, espécie de jogo de tabuleiro, cuja estrutura de movimentos de distribuição e colheita das peças está pautada em conceitos matemáticos e em práticas culturais e filosóficas africanas (PEREIRA, 2011). Algumas propostas também envolviam outros jogos africanos como o shisima, yoté, mbube mbube, pegue o bastão, ubongo, no thaks e yahtzee. Acerca dos conteúdos identificados nas atividades, citamos: sequência numérica, equação, fração, transformações geométricas e construções geométricas. Assim, com esse levantamento bibliográfico, percebeu-se que muitas experiências com Matemática estão relacionadas ao Mancala ou aos outros jogos africanos. Notou-se, também, que há uma carência de trabalhos com enfoque na cultura africana nas produções acadêmicas de Educação Matemática, sobretudo, voltados para a Educação Básica.

Nosso objetivo, neste trabalho, é apresentar e analisar uma oficina ministrada na I Semana da Consciência Negra e Indígena do Ifes - Campus Viana, intitulada "Transformações geométricas em estamparia africanas". O evento foi realizado entres dias 20 e 24 de novembro de 2017 e teve como público principal estudantes do primeiro e do segundo ano do Curso Técnico em Logística Integrado ao Ensino Médio.

Antes, porém, comentaremos um pouco sobre a tecelagem africana, tema principal da nossa oficina, e sobre o Programa Etnomatemática, tendo como base o referencial teórico especifico. Para isso, vamos sintetizar a história da tecelagem africana, abordando a importância dos tecidos para essa cultura, seu simbolismo e a sua utilização como moeda de troca nas antigas sociedades africanas.

\section{Estamparia africana: história e simbolismo}

Uma possível origem da tecelagem africana é evidenciada desde a Era Neolítica, quando os homens utilizavam a essência da tecelagem para entrelaçar pequenos galhos e ramos para construírem barreiras, escudos ou certos. Uma das hipóteses é que a teia de arranha e o ninho de pássaros podem ter sido a fonte de inspiração para esse trabalho. Em Bento e Gonçalves (2010, p. 4) encontramos que

A comprovação cientifica de que a África é o berço da humanidade nos impõe o desafio de pensá-la como local de origem histórica e sócio-político-cultural de todos os povos. E quando ressaltamos os valores e a cultura dos povos africanos reafirmamos a memória civilizatória do continente-mãe. 
A partir de Bento e Gonçalves (2010), podemos, também, destacar algumas importâncias dos tecidos africanos. Cabe citar, por exemplo, que o volume dos tecidos, seu luxo e a procedência das fibras é sinônimo de poder, fato evidenciado pelo uso, visto que os chefes de Estados sempre utilizavam tecidos mais requintados para representar soberania. Ademais, as vestimentas eram vistas como símbolo de prosperidade do grupo e a qualidade, o tamanho e a ornamentação das roupas revelavam a classe social das pessoas. Com isso, os tecidos foram meios de decifrar costumes locais e de compreender um pouco a história de cada lugar.

Para nos situarmos sobre a importância esses tecidos para o povo africano, é importante, ainda, saber que, em cada evento realizado, há uma estampa referente ao acontecimento, incluindo a cor como parte dessa distinção. Esta produção artesanal era transmitida de geração em geração como uma atividade sagrada, porque imitava a obra de Maa Ngala (Mestre Divino) e complementava sua criação (BENTO; GONÇALVES, 2010). As formas geométricas são tradicionais de cada tribo e são chamadas de motivos, pois são representadas no tecido, justamente, por algum motivo. Ainda sobre a relevância dos tecidos, temos um exemplo:

Em Gana e na Costa do Marfim é produzido um tecido rico em sua simbologia chamado Adinkra, que tem símbolos Akan gravado nele. Os símbolos representam provérbios populares, registros de eventos históricos, manifestam determinadas atitudes ou comportamentos relacionados com figuras retratadas ou conceitos exclusivamente relacionados às formas abstratas. É um dos vários panos tradicionais produzidos na região (BENTO; GONÇALVES, 2010, p. 8).

Além dos fatos citados, os tecidos africanos ainda eram empregados como valor de referência por vários séculos e foram utilizados como moeda de troca. Nessa perspectiva, cabe esclarecer que as sociedades africanas tradicionais possuíam uma economia de subsistência, ou seja, produziam o que necessitavam para garantir o sustento da tribo a que pertenciam e os produtos eram trocados de acordo com seu valor de uso e não pelo seu valor de troca. Agora, sabendo um pouco da história e simbolismo das estamparias africanas, nos perguntamos: como incluir essa discussão nas aulas de Matemática? Como elaborar uma oficina para alunos do ensino médio com base nessa cultura? Tentaremos responder a essas perguntas nas próximas seções. 


\section{O programa Etnomatemática}

Nosso trabalho possui como base o Programa Etnomatemática, de D’Ambrósio, que começou a ganhar corpo em meados da década de 1970. Algumas das referências usadas para consulta foram D'Ambrósio (2005) e Gerdes (2012), autores que tratam da possibilidade de uma prática de ensino de Matemática inspirada pela Etnomatemática.

De acordo com D’Ambrósio (2005), os povos têm, ao longo da história, criado e desenvolvido estratégias de reflexão e de observação. Associado à estas, técnicas e habilidades (ticas) para explicar, entender, conhecer, aprender, saber e fazer como resposta à necessidade de sobrevivência e de transcendência (matema), em ambientes sociais e culturais (etno). A abordagem a diferentes formas de conhecer é o princípio do Programa Etnomatemática (idem). Nesse sentido, segundo o pesquisador, podemos, também, interpretá-lo como um programa interdisciplinar que contempla o domínio das chamadas ciências da cognição, da epistemologia, da história, da sociologia e da difusão.

De acordo com os estudos de D’ Ambrósio (2005) sobre Etnomatemática, Gerdes (2012) salienta o que estudos etnomatemáticos analisam:

- tradições matemáticas que sobreviveram à colonização e atividades matemáticas na vida diária das populações, procurando possibilidades de as incorporar no currículo;

- elementos culturais que podem servir como ponto de partida para fazer e elaborar matemática dentro e fora da escola.

(GERDES, 2012, p. 18)

Propostas de ensino com a perspectiva desse programa podem contribuir para a valorização de culturas marginalizadas, sendo que "grande parte dos conteúdos dessa matemática escolar é de origem africana e asiática" (GERDES, 2012, p. 52). Em D’Ambrósio (2005), encontramos referência à passagem anterior ao dizer que preservar e recuperar traços de uma cultura, como as tradições, a culinária, os idiomas e as manifestações artísticas em geral, contribui para a preservação cultural, o que é essencial para estimular a criatividade. Ambos os autores acreditam que a criatividade pode ser melhorada por meio da valorização cultural. Para reforçar as contribuições da Etnomatemática, D’Ambrósio (2005) afirma que somente poderão conduzir a uma visão plena da realidade os indivíduos que forem submetidos ao conhecimento transdisciplinar. Ainda, Gerdes (2012, p. 39) completa, dizendo que o "reconhecimento das práticas e 
tradições científicas populares e a sua incorporação no currículo contribui para o renascimento cultural, por reforçar a autoconfiança cultural”.

A Etnomatemática evidencia-se como um mecanismo importante no processo de ensino e de aprendizagem, pois mostra que a Matemática está presente em todas as culturas humanas, na vida de todos os povos e de todos grupos sociais e culturais e na vida de homens e mulheres. Na verdade, só é possível ter uma visão plena da História da Matemática levando em consideração todas essas ideias matemáticas. Citamos, ainda, que o Programa Etnomatemática se importa em conhecer a evolução do conhecimento científico dos povos nas suas relações com a sociedade e a cultura e sua contribuição para o ensino de Matemáticas.

Em Gerdes (2007, p. 11) encontramos uma passagem que reflete implicitamente potencialidades da Etnomatemática:

\begin{abstract}
expressão 'Matemática Congelada' introduzida por Paulus Gerdes numa das suas conferências; parece-me uma expressão particularmente feliz pois evidencia que, já que não sabemos qual a origem de determinado artefato, podemos imaginar a matemática que levou à sua construção, pois esta está de algum modo 'congelada', embutida, conservada nesse objeto e nós, se tivermos suficiente cuidado e paciência, poderemos tentar 'descongelá-la' e admirá-la. Muitas vezes olhamos para objetos artesanais e não nos apercebemos como pode ser rico o pensamento abstrato que está por detrás da sua manufatura; nem imaginamos que, na realidade, até se podem construir muitas estruturas abstratas, por vezes extremamente complexas, que explicam a estrutura e o funcionamento desses objetos.
\end{abstract}

A incorporação, na sala de aula, de elementos de outras culturas distintas das vivenciadas pelos alunos pode favorecer a educação para uma cidadania tolerante e respeitadora das culturas de outros povos na medida em que os educandos percebam que ideias matemáticas existem em todas as expressões culturais (GERDES, 2007). Diante desses argumentos, podemos concluir que o citado programa pode trazer novas propostas que favoreçam o conhecimento de diversas culturas, mas, sobretudo, que favoreçam uma educação em que os próprios indivíduos não sejam excluídos.

\title{
Metodologia
}

Esta pesquisa, de natureza qualitativa, apresenta e discute uma oficina ocorrida na I Semana da Consciência Negra e Indígena do Instituto Federal do Espírito Santo (Ifes), campus Viana, sobre transformações geométricas em estamparias africanas, em novembro de 2017, com estudantes do primeiro e segundo ano do Curso Técnico em 
Logística Integrado ao Ensino Médio. Optamos pela pesquisa qualitativa por ser uma abordagem para explorar e compreender o significado que indivíduos ou grupos atribuem a um problema social ou humano. Sobre essa perspectiva, Creswell $(2014$, p. 40) descreve que "aqueles que se dedicam a essa forma de investigação sustentam uma maneira de olhar para a pesquisa que honra um estilo indutivo, um foco no significado individual e a importância de tornar a complexidade de uma situação" (tradução nossa).

Com base no Programa Etnomatemática, procuramos planejar uma oficina que contemplasse todos os seus potenciais em sala de aula. Com o levantamento bibliográfico dos anais do ENEM, observamos que existem poucos trabalhos acadêmicos com foco na cultura africana e que existem muitos conteúdos matemáticos que podem ser explorados (SCHUNK; SÁ, 2018). Assim, decidimos criar uma abordagem pedagógica referente ao Programa Etnomatemática, com foco em África. Planejamos diversas reuniões para discutirmos os conteúdos matemáticos que poderíamos explorar e quais aspectos da cultura africana poderíamos utilizar. As nossas ideias trilharam vários caminhos até chegar no presente tema deste trabalho. No início do planejamento, cogitamos trabalhar com mosaicos (SOUZA, 2016) ou pinturas no pano com símbolos africanos (BENTO; GONÇALVES, 2010), no entanto, optamos por discutir as transformações geométricas a partir de estamparias africanas.

Durante a oficina, abordamos o conteúdo de simetria, de translação, de reflexão e de rotação. Nosso objetivo era analisar as estamparias africanas a fim de reconhecer as transformações geométricas presentes nos tecidos, além de realizar investigações por meio dos símbolos africanos para, então, aflorar as habilidades de construções das transformações. Para isso, discutimos a importância das estamparias e dos símbolos na cultura africana, identificamos as transformações geométricas e as exploramos por meio da simbologia daquela cultura.

A oficina contou com a participação de 13 estudantes e durou 2 horas, divididas em quatro momentos. O primeiro consistia na introdução, por meio de uma apresentação de slides, que abordou a origem da tecelagem africana, explicitando seu simbolismo e sua importância como moeda de troca para as antigas sociedades. Desse modo, objetivamos contextualizar a oficina por meio de uma vertente histórica.

O segundo momento foi reservado para a investigação das transformações geométricas presentes nas estamparias africanas. Nesta etapa, foi entregue, para cada 
Thaciane Jähring Schunk, Lauro Chagas e Sá

Abordagem Enomatemática para transformações geométricas a partir da tecelagem africana

grupo de estudantes, um tipo diferente de estamparia africana impressa em folha de papel sulfite, tamanho A4. Eles ficaram incumbidos de analisar as transformações geométricas na estamparia e de realizar o registro das impressões tidas em uma folha de caderno. Neste momento, tivemos como objetivo a compreensão e a visualização do aluno de uma das maneiras como a matemática se faz presente na cultura africana.

O terceiro momento foi destinado à apresentação das análises de cada grupo, sendo as estamparias projetadas para toda a turma. O objetivo desta etapa foi a socialização da matemática e das transformações geométricas presentes nas estamparias.

Já no quarto momento, foi entregue, para cada aluno, uma folha com sete atividades sobre as transformações geométricas com símbolos africanos. Nesta etapa, objetivamos aprofundar, por meio dos símbolos africanos, o estudo das transformações, visto que nesse momento eles iriam utilizar os símbolos para realizarem as transformações, diferentemente do que foi realizado nos momentos anteriores.

Como método de análise da oficina, utilizamos questionário diagnóstico antes e depois da proposta didática com o objetivo de analisar a contribuição da oficina para os alunos sobre a relação entre a estamparia africana - cultura - e a matemática. Também consideramos as folhas de registro para compreender as dificuldades que os alunos enfrentaram nesse tipo de abordagem.

Para a análise dos dados, selecionamos três questões da folha de atividades, respectivamente, as de número 3, 4 e 5. Na questão 3, analisamos a criatividade, enquanto, nas questões 4 e 5, investigamos as diferentes estratégias de solução dos alunos. Em todos esses casos, buscamos utilizar nos enunciados das atividades uma linguagem mais próxima possível da cultura africana, como pode-se observar nas questões abaixo: 
Thaciane Jähring Schunk, Lauro Chagas e Sá

Abordagem Enomatemática para transformações geométricas a partir da tecelagem africana

Figura 1 - Parte da atividade proposta

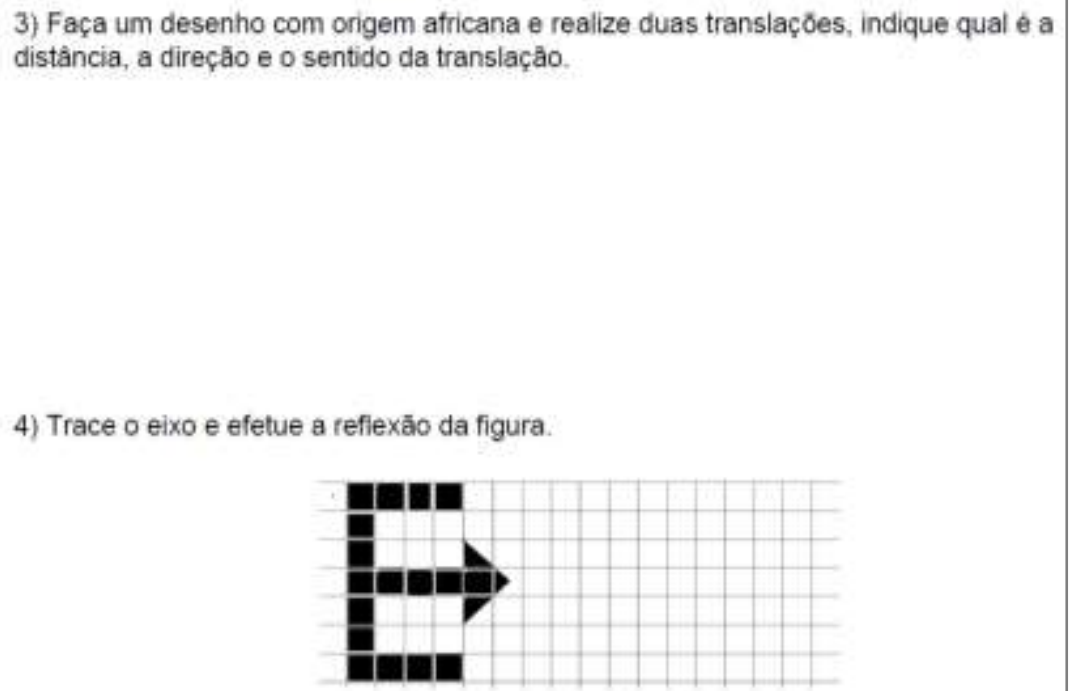

Fonte: Arquivo pessoal, 2017.

Figura 2 - Parte da atividade proposta

5) Esboce a imagem rotacionada de cada motivo abaixo, considerando o sentido horario e o centro de rotaçāo dado.
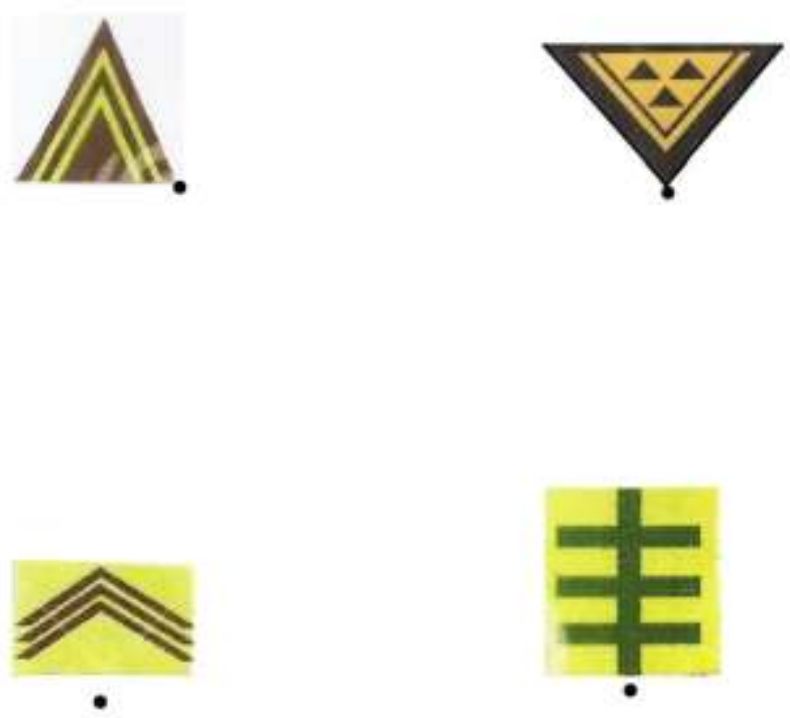

Fonte: Arquivo pessoal, 2017.

\section{Análise dos dados}

Observamos, na terceira questão, que a maioria dos alunos criou alguma imagem. Eles usaram a criatividade ao produzir imagens que tinham trações e/ou características africanas, não reproduzindo imagens que já haviam visto nas estamparias disponibilizadas. Os educandos, ao observar os símbolos africanos e reconhecer que são formados por figuras geométricas (motivos), como triângulos e quadrados, buscaram 
Thaciane Jähring Schunk, Lauro Chagas e Sá

Abordagem Enomatemática para transformações geométricas a partir da tecelagem africana

realizar seus motivos com base nisso, além de usarem as transformações geométricas na sua criação. Seguem alguns desenhos produzidos pelos estudantes:

Figura 3 - Desenho do aluno Diego

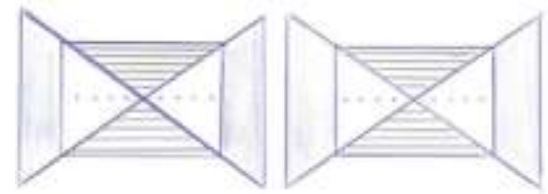

Fonte: Arquivo pessoal, 2017.
Figura 4 - Desenho do aluno Maurício

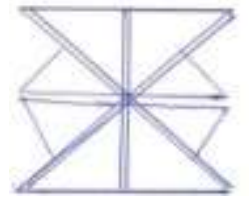

Fonte: Arquivo pessoal, 2017.

Na figura 4, podemos observar que o aluno Diego usou formas com retângulo, triângulo, segmento de retas e pontos, formando uma imagem que tem eixos de simetria, reflexão e ponto de rotação. O aluno Maurício utilizou triângulos, na figura 5, formando uma imagem que possui as mesmas características da imagem do aluno Diego. O interessante desses desenhos é os quão detalhistas foram, pois extraíram as características dos motivos representados nas estamparias africanas e criaram imagens com todos os detalhes de um motivo.

$\mathrm{Na}$ quarta questão, os alunos representaram o eixo de reflexão em diferentes lugares, tendo assim, várias respostas diferentes. No entanto, a maioria efetuou o eixo próximo da figura. Já na quinta questão, os educandos utilizaram diferentes estratégias para realizarem as rotações. O primeiro motivo era para ser rotacionado $180^{\circ}$, o segundo $90^{\circ}$, o terceiro $210^{\circ}$ e o quarto $135^{\circ}$. Alguns alunos utilizaram como referência para a rotação apenas um segmento de reta, levando o resto do motivo junto, outros fizeram um quadrilátero entorno do motivo e rotacionaram o quadrilátero com o desenho dentro. Podemos comentar que esta questão foi uma das mais desafiadoras para eles, visto que alguns estudantes confundiram o ponto de referência para a rotação. Seguem dois exemplos que ilustram as diferentes estratégias as quais citamos: 
Figura 5 - Resposta do aluno Paulo
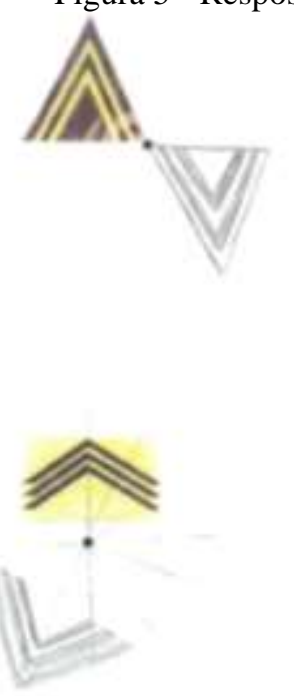

Fonte: Arquivo pessoal, 2017.
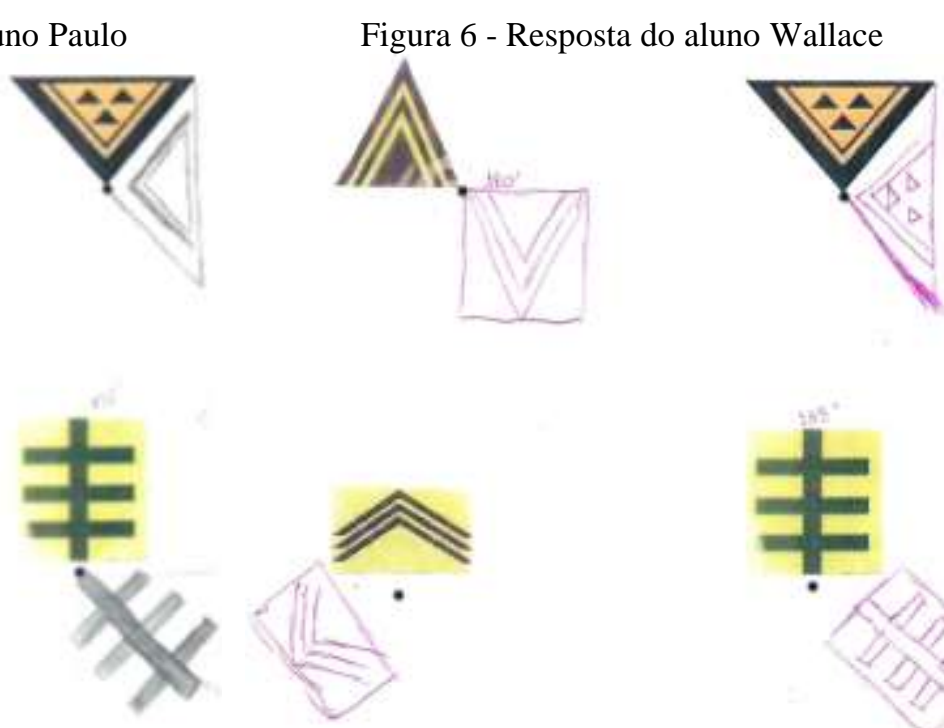

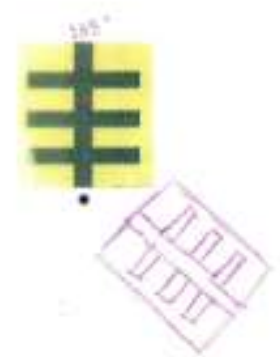

Fonte: Arquivo pessoal, 2017.

Para identificar os indícios da contribuição da oficina para a formação dos estudantes, utilizamos o mesmo questionário antes e depois do encontro. No questionário havia a seguinte questão: comente o que sabe sobre as estamparias africanas em relação à sua cultura e à Matemática. Após a realização da oficina, dos treze participantes, sete estudantes $(53,8 \%)$ atingiram nossas expectativas, identificando o conhecimento histórico e matemático sobre o tema; cinco educandos $(38,4 \%)$ atingiram parcialmente nossas expectativas, ou seja, avançaram ou na parte histórica, ou na parte matemática; e um discente $(7,6 \%)$ não alcançou nossas expectativas, pois não houve nenhum avanço da resposta do primeiro para o segundo questionário. Com isso, a partir da análise desses resultados, acreditamos que a oficina contribuiu positivamente para o conhecimento dos alunos sobre a relação entre a estamparia africana e a Matemática.

\section{Algumas considerações}

Ao refletir sobre essa oficina percebemos que podemos repensar duas questões. A primeira é sobre a terceira questão da folha de atividades, na qual poderíamos ter solicitado aos alunos para, além de desenharem, darem nome aos seus desenhos, com a intenção de, assim, aproximarmo-nos mais da cultura africana, visto que, para os africanos, estes desenhos se chamavam motivos e possuem um significado. Consideramos que se trata de um detalhe que pode fazer muita diferença, uma vez que incorpora 
Thaciane Jähring Schunk, Lauro Chagas e Sá

Abordagem Enomatemática para transformações geométricas a partir da tecelagem africana

elementos de outra cultura na forma de comunicação proposta em sala de aula. Ao realizar esse tipo de trabalho, temos que tentar nos apropriar o máximo possível da cultura do lugar. Além disso, esse aspecto deve ser muito bem refletido durante toda a oficina, não somente no início, em que está mais evidente a parte histórica e cultural. A segunda questão é sobre uma atividade em que o enunciado não ficou bem escrito, pois nenhum aluno interpretou como os autores pretendiam. Segue:

Figura 7 - Atividade

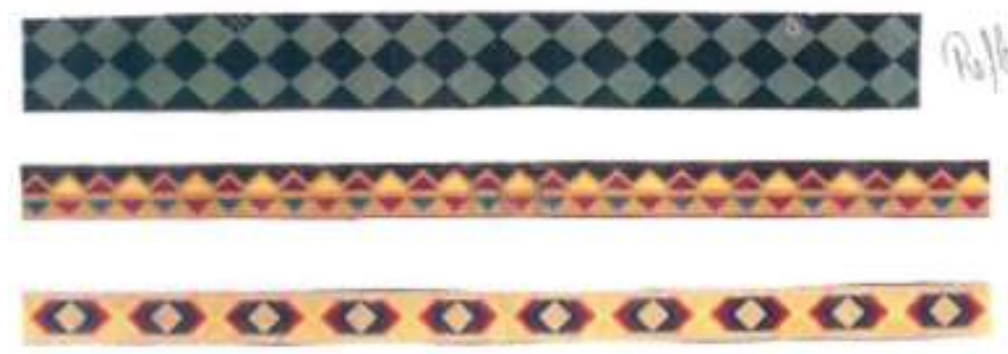

Fonte: Arquivo pessoal, 2017.

Pretendíamos que os discentes realizassem pelo menos alguns eixos de simetria ou reflexão, mostrassem algum exemplo de onde ocorre a translação e rotação, ou seja, descrevessem explicando, no entanto, temos consciência de que poderíamos ter redigido melhor o enunciado. Todos os alunos descreveram muito brevemente o que visualizaram, como no exemplo anterior.

Acreditamos que este trabalho está em consonância com a Lei 10.639/2003, valorizando a cultura africana no contexto escolar e que pode servir como base para a realização de outros trabalhos. Apesar de ter realizado a oficina durante um evento específico, esperamos que atividades como estas não sejam produzidas somente na semana da consciência negra, mas em qualquer época do ano. Conhecemos os desafios e sabemos que não é fácil planejar algo tão atípico no campo da Educação Matemática, contudo, enquanto pesquisadores, precisamos contribuir na produção acadêmica de estudos com foco nas diversas culturas, a fim de incentivar outros profissionais da educação a incorporá-los no seu trabalho pedagógico, promovendo uma valorização as culturas e riquezas dos povos africanos. 


\section{Referências}

BENTO, Marlene de Fátima; GONÇALVES, José Henrique Rollo. Tecidos Africanos: Histórias Estampadas. In: PARANÁ (ESTADO). Secretaria de Educação O professor PDE e os desafios da escola pública paranaense. Curitiba: SEED/PR, 2010, v. 01.

BRASIL. Casa Civil. Lei 10.639, de 09 de janeiro de 2003. Altera a lei nº.394, de 20 de dezembro de 1996, para incluir no currículo oficial da Rede de Ensino a obrigatoriedade da temática "História e Cultura Afro-Brasileira" e dá outras providências. Brasília, 2003. Ministério da Educação/Secretaria de Educação Continuada, Alfabetização e Diversidade. Diretrizes Curriculares nacionais para a educação das relações étnico raciais e para o ensino da História e Cultura Afro Brasileira e Africana na educação básica. Brasília - DF: MEC/Secad, 2004.

CORENZA, Janaina de Azevedo; MELQUIADES, Mariana; SOUZA, Cleyton Brito de. Aprender jogando: experiência com a lei 10.639/2003 na formação de professores. In: Encontro Nacional de Educação Matemática, XII. São Paulo - SP. Anais eletrônicos, 2016.

CRESWELL, John W. Research design: qualitative, quantitative, and mixed methods approaches. 4th ed. California: SAGE Publications, 2014.

D’AMBRÓSIO, Ubiratan. Sociedade, cultura, matemática e seu ensino. Revista Educação e Pesquisa, São Paulo, v. 31, p.99-120, 2005. Disponível em: <http://www.revistas.usp.br/ep/article/view/27965>. Acesso em: 04 set. 2017.

EVES, Howard. Introdução à História da Matemática. Tradução de Hygino H. Domingues. 2.ed. Campinas, SP: Editora da UNICAMP, 1997.

GERDES, Paulus. Etnomatemática: Reflexões sobre Matemática e Diversidade Cultural. Ribeirão, Portugal: Edições Húmus, 2007.

Etnomatemática - Cultura, Matemática, Educação: Colectânea de Textos 1979-1991. 2012. Disponível em: <http://www.lulu.com/shop/paulusgerdes/etnomatem $\% \mathrm{C} 3 \% \mathrm{~A} 1$ tica-cultura-atem $\% \mathrm{C} 3 \% \mathrm{~A} 1$ ticaeduca $\% \mathrm{C} 3 \% \mathrm{~A} 7 \% \mathrm{C} 3 \% \mathrm{~A} 30-$ colect\%C3\%A2nea-de-textos-1979-1991ebook/ebook/product-21323859.html>. Acesso em: 03 jan. 2018.

PEREIRA, Rinaldo Pevidor. O jogo africano mancala e o ensino de matemática em face da Lei 10.639/03. 2011. 156f. Dissertação (Mestrado em Educação) - Universidade Federal do Ceará, Faculdade de Educação, Programa de Pós-Graduação em Educação Brasileira, Fortaleza-CE, 2011.

SCHUNK, Thaciane Jähring; SÁ, Lauro Chagas e. Um mapeamento de trabalhos de Educação Matemática com foco na cultura africana. In: $5^{\circ}$ Simpósio Internacional de Pesquisa em Educação Matemática, 2018, Belém - PA. Anais, 2018. (no prelo). 
Thaciane Jähring Schunk, Lauro Chagas e Sá

Abordagem Enomatemática para transformações geométricas a partir da tecelagem africana

SILVA, Petronilha Beatriz Gonçalves e. Aprender, ensinar e relações étnico-raciais no Brasil. Educação. Porto Alegre/RS, ano XXX, n.3, v. 63, p.489-506, set/dez. 2007. Disponível em: $<$ http://revistaseletronicas.pucrs.br/ojs/index.php/faced/article/download/2745/2092>. Acesso em: 20 out. 2017.

SOUZA, Valdirene Rosa de. A arte do mosaico no estudo do conceito geométrico. In: Encontro Nacional de Educação Matemática, XII. São Paulo - SP. Anais eletrônicos, 2016. 